\title{
Human milk bank and personalized nutrition in the NICU: a narrative review
}

\author{
Manuel Sánchez Luna ${ }^{1}$ (1) • Sylvia Caballero Martin ${ }^{1} \cdot$ Carmen Sánchez Gómez-de-Orgaz ${ }^{1}$
}

Received: 13 October 2020 /Revised: 14 November 2020 / Accepted: 20 November 2020 / Published online: 27 November 2020

(C) Springer-Verlag GmbH Germany, part of Springer Nature 2020

\begin{abstract}
The number of infants born preterm including extremely premature babies is rising worldwide, particularly in low- and middleincome countries, which challenge neonatologists and milk banks for the provision of the most adequate nutrition for successful infant's growth and development. The benefits of mother's own milk (MOM) have been extensively recognized, but the use of donor milk (DM) is a commonly routine practice in preterm neonates admitted to the NICU. Pasteurized mature milk from milk banks is not the same composition than the mother's colostrum and premature milk, the characteristics of which protect the infant from the risk for necrotizing enterocolitis, late-onset sepsis, and other comorbidities associated with prematurity. The development of a personalized nutrition unit (PNU) allows to obtain DM from mothers who have their infants admitted to the NICU and produce an excess of milk, a practice that matches MOM by gestational age and the stage of lactation, ensuring an adequate composition of DM to target the nutritional requirements of premature infants.

Conclusion: This narrative review presents salient data of our current knowledge and concerns regarding milk feeding of preterm infants in the NICU, with special emphasis on personalized DM as a result of establishing a PNU.
\end{abstract}

\section{What is Known:}

- Donor milk bank is mature or pooled milk from lactating mothers at different stages of lactation.

- Milk composition varies by gestational age and stage of lactation.

What is New:

- Donor milk from mothers delivered prematurely have the most adequate composition for preterm infant feeding.

- Personalized nutrition for premature infants with preterm donor milk is feasible.

Keywords Donor milk · Milk bank · Personalized nutrition · Prematurity

\section{Abbreviations \\ DM Donor milk \\ IgA Immunoglobulin A}

Communicated by Daniele De Luca

Manuel Sánchez Luna

msluna@salud.madrid.org

Sylvia Caballero Martin

sylvia.caballero@salud.madrid.org

Carmen Sánchez Gómez-de-Orgaz

msgomezdeorgaz@salud.madrid.org

1 Neonatology Department, Hospital General Universitario Gregorio Marañón, Universidad Complutense, C/ O’Donnell 48,

E-28009 Madrid, Spain
HMOs Human milk oligosaccharides

HoP Holder pasteurization

HPP High-pressure processing

HTST High-temperature short-time

LOS Late-onset sepsis

NEC Necrotizing enterocolitis

NICU Neonatal intensive care unit

MOM Mother's own milk

PNU Personalized nutrition unit

\section{Introduction}

Every year, an estimated 15 million babies are born preterm and these numbers are rising $[1,2]$. Appropriate nutrition is a 
critical factor in efforts to improve survival and outcomes of extremely and very preterm babies [3-5]. The mother's own milk (MOM) composition differs from mature or term human milk, and these differences far from being an inconvenient should be viewed as an advantage due to individual characteristics in the content of most of nutrients and other important components [6]. If pasteurized human donor milk (DM) should be given, a DM milk from a similar gestational and lactation stage would be the best option. However, most of the standard human milk banks use a composite of pooled expressed term milk at any times over lactation, and in many cases, mature milk is far from having the characteristics of the MOM of extremely or very preterm infant [7, 8]. In these circumstances, a personalized premature DM would be an ideal approach. This narrative review aims to give an overview of current knowledge and concerns regarding milk feeding of preterm infants in the NICU, with special emphasis on personalized DM.

\section{Differences in the composition of preterm milk and term milk}

Low protein intake is the primary limiting factor for growth failure in preterm infants, and the mother of a premature infant produces individualized breast milk to the infant for a better nutrition due to the higher protein needs. In 1980, Schanler and $\mathrm{Oh}$ [9] already showed that the total content of nitrogen in the milk of mothers of premature infants was significantly higher during the initial 2 weeks of lactation and regressed towards term milk by 1 month. They also noted the lower milk volume consumed by preterm babies as compared with the mothers' supply, suggesting the possibility of storing and using this excess of mothers' milk to feed premature infants as the best possibility to ensure a positive nitrogen balance. In a longitudinal analysis of breast milk from 102 mothers who had delivered preterm infants and from 10 mothers who had delivered term infants, the more immature the breast milk, the higher protein content, with an average of protein in preterm infants of $<28$-week gestation of $2.3 \pm 0.5 \mathrm{~g} / \mathrm{dL}$, compared with $1.9 \pm 0.3 \mathrm{~g} / \mathrm{dL}$ at 32-33 weeks [10]. In a meta-analysis of 41 observational studies, protein and fat content was higher in breast milk of preterm infants compared with full-term newborns during the first 10-12 weeks of lactation [11].

Free amino acids play an important role in postnatal development [12], with glutamic acid and glutamine comprising nearly $50 \%$ of total free amino acid content of breast milk [13]. In a systematic review of preterm and term human milk based on 83 studies, the majority of the variation in amino acid composition was caused by the stage of lactation, with glutamine 20 times higher in mature milk and its lowest value in colostrum [14]. Of the only six studies with data of free amino acids from preterm milk (average 12.5 postpartum days), total amino acids and total nitrogen levels were higher in preterm milk, with a significantly greater content in valine, threonine, and arginine, with the exception of glutamine, which was significantly lower by nearly onehalf in preterm than term human milk. Therefore, preterm milk may be a more appropriate source of protein and certain amino acids than term milk to accommodate for the rapid growth rates of premature infants [14].

Lipid composition of beast milk is also influenced by gestational age at bith, with differences in the profiles of lipid classes and fatty acid and triglyceride contents of colostrum [15]. In a longitudinal study of lactating mothers, including 27 preterm deliveries (gestational age $30.8 \pm 1.4$ weeks) and 34 term deliveries (gestational age $39.5 \pm 1.0$ weeks), total lipids varied from an mean of 2.4 to $1.7 \mathrm{~g} / 100 \mathrm{~mL}$ in preterm versus term colostrum, and from 3.1 to $3.6 \mathrm{~g} / 100 \mathrm{~mL}$ in preterm versus term mature milk, with significant differences in total lipid content in mature milk only. A higher content of saturated fatty acids with a major contribution of medium chain fatty acids was found in preterm milk. These differences in total lipids and fatty acids support that human milk from mothers with preterm deliveries collected in milk banks would be more appropriate if DM should be given to preterm babies as supplemental or full feeding methods.

Human milk oligosaccharides (HMOs) are non-digestible carbohydrates that act as bioactve compouns and exert multiple beneficial functions, such as support of colonization of the gut microbiota, reduction of pathogenic infections, and support of immune development [16]. All HMOs are synthesized in the mammary gland, with higher concentrations during the early stages of lactation and gradual decrease over time. HMO categories include fucosylated neutral HMOs, sialylated acidic HMOs, and non-fucosylated neutral HMO, with diversity of HMO based on genetic background of the mother, which includes combinations of the FUT2 or secretor gene that encode flucosyltransferase-2 and the FUT3 gene that encodes flucosyltransferase-3 (Lewis blood group) $[17,18]$. In European countries, $77 \%$ of the population is expected to be FTU2 secretor positive [19], and it is possible that milk from non-secretor mothers may be less protective against necrotizing enterocolitis (NEC) than milk from secretor mothers [20]. Delayed maturation of microbiota is a potential risk factor for NEC, and human milk rich in fucosylated neutral HMOs has protective effects against alterations in the intestinal microbiota (dysbiosis) [21]. Holder pasteurization (HoP) does not modify HMO content in milk from mothers delivered at 23 and 36-week gestation, so their biological value and potential benefits in preventing NEC and other mobidities of prematurity are maintaned in DM [22].

\section{Mother's own milk in preterm infants}

Benefits of feeding premature infants with MOM are associated with componentes of colostrum [23] (e.g., epidermal growth 
factor and transforming growth factor- $\alpha$ ); the concentration of trophic peptides in milk from mothers of extremely preterm infants (23-27 weeks) is higher than in preterm and full-term milk throughout the first month of lactation, with significant healing effects on injured gastrointestinal mucosa [24].

When preterm infants are fed with MOM, there is a reduction in the ocurrence of NEC and/or late-onset sepsis of up to $50 \%$ as compared with infants fed with DM or preterm formula milk $[25,26]$. In a systematic review and meta-analysis of human milk feeding and morbidity in very-low-birthweight (VLBW) infants, including 6 randomized trials (RCTs) with 1472 infants and 43 observational studies with 14,950 infants, the administration of either exclusive human milk or any human milk compared with exclusive preterm formula reduced NEC [27]. Moreover, a higher proportion of human milk was more effective than lower amounts with a $4 \%$ absolute risk reduction in any NEC. Human milk also showed a possible reduction in late-onset sepsis, severe retinopathy of prematurity, and severe NEC. However, differences between unpasteurized and pasteurized human milk on any or severe NEC were not found [27]. In a metaanalysis of observational studies, DM supplementation reduced bronchopulmonary dysplasia, although in the same study, the meta-analysis of RCTs could not demonstrate that supplementation of MOM with DM reduced bronchopulmonary dysplasia when compared with preterm formula [28]. It has been reported that preterm infants of 28 to 32 weeks benefit more than those under 28 when using DM in terms of NEC reduction [29]. On the other hand, a less protective effect of pasteurized DM compared with MOM has ben proposed, supporting in part the different effect on some of the morbidities of preterm infants fed with pasteurized DM, as most of the anti-inflammatory cytokines are lost, except for the pro-inflammatory cytokine IL-8 [30].

In relation to bioactive compounds found in breast milk, the most oustanding are antioxidants, the highest levels of which are found in the colostrum and decreasing along the lactation period. Levels are also higher in preterm as compared with full-term milk [31], probably indicating the need of a greater protection during the first days after delivery, mostly in preterm infants.

Finally, in a recent study of the microbiota in the preterm mother's milk, the temporal dynamics of microbial communities in 490 breast milk samples from 86 mothers of preterm infants (born $<1250 \mathrm{~g}$, mean $27.6 \pm 2.6$ weeks of gestation) were characterized [32]. It was found that the microbial signature was unique to each mother and changed over time. This is a relevant finding reinforcing the importance of MOM feeding.

\section{Composition of human milk banks}

The majority of human milk banks have donors of at least 15 days after delivery, with around 3 months of the infant's life at the beginning of donation. Consequently, most of all pasteurized milk is mature. In addition, pooled milk is used to include milk donors at different stages of lactation. Standardized pooling practice, however, helps to homogenize the macronutrient content and standard fortification, but concerns remain regarding the adequacy of pasteurized human DM as a sole source of nutrition for premature infants [33]. If unfortified milk is used, the median feeding volumes to reach protein targets of 3.5 to $5.0 \mathrm{~g} / \mathrm{kg}$ range between 269 and $490 \mathrm{~mL} / \mathrm{kg}$ of body weight, with lower volumes required for transitional milk compared with mature milk due to the higher protein content during the transitional stage [34].

Standard fortification usually fails to supply enough protein content to reach the recommendation of 3.5-4.5 g/ $/ \mathrm{kg} /$ day for VLBW infants [35], and slow growth rates have been reported in VLBW infants fed with standard fortification of human milk [36]. Targeted fortified DM is the preferred mode of fortification [37], although the high variability of macronutrient content among mothers of VLBW infants may be an inconvenience [38]. Most of the target fortification is done by 2 -week analysis of macronutrient content [39]. In a comparative study of targeted and standard fortification of human milk in preterm infants, weekly weight gain and daily growth rates were higher in the target fortification group than in infants receiving standard fortification, with an adequate metabolic tolerance and osmolarity of the brest milk of $300 \pm 16$ $\mathrm{mOsm} / \mathrm{kg}$ and $376 \pm 66 \mathrm{mOsm} / \mathrm{kg}$ before and after fortification, respectively [37].

In a systematic review of 12 RCTs or quasi-RTC studies comparing feeding with formula versus DM in 1879 preterm or VLBW infants, formula-fed infants showed higher inhospital rates of weight gain, linear growth, and head growth, although formula feeding increased the risk of NEC [40]. In a meta-analysis of studies adressing the association between DM and surgical NEC, a clear protective effect of DM on the surgical cases of NEC as compared with preterm formula was not found [41]. In a multicenter, double-blind randomized clinical trial in 373 VLBW infants, there were no significant differences between pasteurized DM and preterm formula for preventing serious infections, NEC, and all-cause mortality during the first 10 days of life [42].

However, DM presents some limitations in relation to the impact of different methods of pasteurization on bioactive substances contained in human fresh milk. In a study of 48 human milk samples, both HoP and flash methods of pasteurization showed significan reduction of Escherichoa coli growth, but the bactericidal activity of human milk was better preserved by the HoP technique [43]. In another study, the analysis of human milk samples over 6 months of lactation before and after HoP showed that HoP reduced human milk lactoferrin, immunoglobulin fractions, and glutathione peroxidase activity [44]. These compounds should be replaced by milk banks after the HoP step to recover lost functionality 
[44]. In a comparison of $\mathrm{HoP}$ and high-temperature short-time (HTST) pasteurization methods on the protein profile of human milk, HTST seemed to better retain some key active componente of DM, including bile salt-stimulated lipase, lactoferrin, and, to some extent, immunoglobulin A (IgA) [45]. In a recent study that compared HoP with HTST and high-pressure processing (HPP) methods, lactoferrin and secretory IgA were preserved by HTST, but significantly reduced with HPP only, whereas lactoferrin was markedly reduced by HoP and HTST, and preserved by HPP [46]. Variations in protein profiles were observed for all processing techniques, being more relevant for HoP. All three methods lowered untreated human milk microbial counts. However, further studies are needed at characterizing residual protein bioactivity with HTST and HPP processing methods. At present, HTST and HPP are considered as the most promising alternatives to HoP for DM banks.

\section{Preterm donor milk for premature infants}

Due to the high interindividual variability and the specific characteristics of the preterm human milk, mostly during the first week after delivery, an attractive possibility based on these physiological aspects is to supply with preterm DM to those immature infants who need supplemental milk. As most standard milk banks use mature human milk, and in most cases from term milk, the use of preterm DM at a similar gestational age and stage of lactation could be more beneficial for preterm nutrition. Although this is a logical and appealing approach, only a few milk banks are able to offer preterm human milk, and what is also of importance, colostrum and transitional preterm DM.

In a single-center study that evaluated the contribution of the milk donation to an Italian milk bank by women who gave birth to premature infants of gestational age $<35$ weeks, the authors demonstrated the feasibility of using preterm DM for premature infants [47]. Mothers donated the excess of milk after feeding their own infants. During a 7 -year study period, a total of $2236 \mathrm{~L}$ of milk were obtained. There were 38 donors (5.7\%) of gestational age $<35$ weeks, 7 donors $(18.4 \%)$ were mothers of extremely premature infants with gestational age $\leq$ 25 weeks, 1 donor gave birth at 25 weeks, 1 donor at 24 weeks, and 4 donors at 23 weeks. It should be noted that one women at an extreme gestational age of 22 weeks succeeded at donating about $4 \mathrm{~L}$ of milk within the 6 days during which the newborn baby was alive. Interestingly, the 7 donors giving birth before the 25 weeks gave $100,360 \mathrm{~mL}$ to the milk bank corresponding to $22.5 \%$ of the entire "preterm" donation. After pasteurization, there was a mean reduction of $25 \%$ of the protein content and of $29 \%$ of the lipid content with a loss of $13 \%$ for the energetic value. This study demonstrates that mothers of preterm infants are able to donate milk to the milk bank, as that amount of milk represent $20 \%$ of the total amount of the donated milk.

The possibility of having donors from mothers of newborns admitted to the neonatal intensive care unit (NICU) contributes to improve the amount of DM to the milk bank. In a retrospective observational study of the donors (mean age $21.6 \pm 2.7$ years) of the National Human Milk Bank in India, $62.3 \%$ of the donors were mothers of newborns admitted to the NICU [48]. Of the total volume of $413 \mathrm{~L}$ of human milk donated, $65.5 \%$ of the donated milk was from mothers who had delivered prematurely and $20.8 \%$ was donated by mothers who had delivered preterm infants with gestational age $<32$ weeks. In low- and middle-income countries, predominant donors of a human milk bank are of a younger age group and more likely to have delivered a premature or a low birth weight baby, most of them requiring NICU admission. In a cross-sectional survey study conducted with 737 human milk donors in Brazil, $47 \%$ of first-time donors and $43.9 \%$ of the regular donors were mothers of preterm infants [49].

\section{Personalized nutrition unit}

We would like to report the experience of establishing a personalized nutrition unit (PNU) in the Neonatology Department of a tertiary care hospital in Madrid (Spain). In April 2018, the PNU was created with the main objective of promoting DM from mothers who have their newborns hospitalized at the NICU and produced an excess of milk for their infants. However, the main focus of the PNU was to obtain the more appropriate DM for a high risk infant admitted to the NICU who needs to be supplemented or fully feed, with target fortification after quantitative analysis of macronutrients. DM is extracted, preserved, transported, and processed (including a microbiological analysis, pasteurization, and classification according to gestational and chronological age), and finally distributed to infant receptors as needed.

From April 2018 to August 2020, 282 donors donated to 659 infants, with a total of $1138.43 \mathrm{~L}$, of them finally pasteurized 1028.27 L. A total of $155(55 \%)$ of the mothers were preterm delivered, of them 3 at 23 weeks, 7 at 24 weeks, 11 at 25 weeks, 11 at 26 weeks, 11 at 27 weeks, 49 at 28 32 weeks, and 63 at $32-37$ weeks. Most of the receptors were immature infants of less than $1500 \mathrm{~g}$ at delivery but also neonates with congenital cardiac disease, asphyxia, or other serious conditions.

DM is classified and matched to the receptor by gestational age and stage of lactation without pooling of different donors, to keep traceability of the milk. After pasteurization, target fortification is done based on macronutrient content analysis (MilkoScan, Foss Asure milk analyzer). After the instauraton of the PNU, any MOM feeding increased from $90 \%$ of the preemies to $98.8 \%$ before and after development of the PNU, 
and exclussive MOM feeding increased from 39 to $55 \%$. We found a clear difference in total protein content by gestational age and lactation, with a mean of $2.25 \mathrm{~g} / 100 \mathrm{~mL}$ of colostrum at $<28$ weeks of gestation, $2.13 \mathrm{~g} / 100 \mathrm{~mL}$ at $28-32$ weeks, $1.98 \mathrm{~g} / 100 \mathrm{~mL}$ at $28-37$ weeks, and $2.01 \mathrm{~g} / 100 \mathrm{~mL}$ at $>37$ weeks. These higher protein contents were observed for transitional and mature milk. Also, the total lipid content varies with gestational age and lactation being the higher content at the lower gestational age for colostrum, transitional, and mature milk. A limitation is that results of HMO content are still not available. A futher consideration is that we have not performed measurement of PNU milk samples versus standard DM milk samples.

The establishment of PNU was also associated with a decrease in NEC and late-onset sepsis. In a before-and-after study, we found a significant reduction of NEC in preterm infants of $<32$ weeks of gestation, from $10.9 \%(12 / 110)$ to $2.4 \%$ (2/84), and late-onset sepsis from 14.7 cases/1000 days of central lines to 9.5 cases/1000 days of central lines, with a shorter use of central venous catheters for parenteral nutrition and a better growth during hospitalization. A survey among donors and mothers of newborn receptors revealed a high satisfaction level with this practice. A limitation, however, is that full data showing an increase of the actual intake of bioactive substances contained in PNU milk samples and putatively associated with protection from infections and NEC are not available.

Interestingly, during the lockdown of the COVID-19 pandemic, the amount of DM increased rather than decreased as mothers were with their infants (rooming-in) during their stay in the hospital as the median raw milk donated per month was $63.5 \mathrm{~L} /$ month before the pandemic, and during the lockdown, it was $111.92 \mathrm{~L}$ in March, 106.88 L in April, and 91.2 L in May 2020.

\section{Conclusion}

It is well stablished that MOM is the most convenient nutrition for any newborn, even more for the more fragile immature infants. When this is not possible or the MOM amount is not enough, DM is an alternative. The quality of the DM for the best nutritional support is still to be defined. As the composition of the milk varies with the gestational age and stage of lactation, a personalized feeding with DM from mothers who deliver prematurely, and target fortified is feasible and probably the better approach. However, data on donation of MOM of premature infants to milk banks are still scarce, but tailoring breast milk and gestational age at delivery for the feeding of the premature infant is the natural way to provide the most adequate nutrition to facilitate healthy growth and the development. Development of PNUs will undoubtedly contribute to the promotion and support of the breastfeeding in NICU, as well as the storage of the milk in the NICU thanks to the mothers of premature babies. Human milk represents not only the better nutrition to infants but one of the most important therapy for our sick babies, and a better knowledge of its biological characteristics will return into more innovative aspects of its medical use.

Acknowledgments The authors thank Marta Pulido, MD, for editing manuscript and editorial assistance.

Authors' contributions MSL design and create the original work of the PNU, review the literature, and wrote the review. SCM and CSGO obtain the data from the PNU and review the manuscript.

Data availability Data are available for review.

\section{Compliance with ethical standards}

Competing interests The authors declare that they have no conflict of interest.

Ethics approval and consent to participate N/A

Consent for publication All the authors consent for publications.

\section{References}

1. World Health Organization (2018) Preterm birth. Available from: https://www.who.int/news-room/fact-sheets/detail/preterm-birth. Date accessed: October 8, 2020

2. Chawanpaiboon S, Vogel JP, Moller AB, Lumbiganon P, Petzold M, Hogan D, Landoulsi S, Jampathong N, Kongwattanakul K, Laopaiboon M, Lewis C, Rattanakanokchai S, Teng DN, Thinkhamrop J, Watananirun K, Zhang J, Zhou W, Gülmezoglu AM (2019) Global, regional, and national estimates of levels of preterm birth in 2014: a systematic review and modelling analysis. Lancet Glob Health 7:e37-e46. https://doi.org/10.1016/S2214109X(18)30451-0

3. Myrhaug HT, Brurberg KG, Hov L, Markestad T (2019) Survival and impairment of extremely premature infants: a meta-analysis. Pediatrics 143:e20180933. https://doi.org/10.1542/peds.2018-0933

4. McNelis K, Fu TT, Poindexter B (2017) Nutrition for the extremely preterm infant. Clin Perinatol 44:395-406. https://doi.org/10.1016/ j.clp.2017.01.012

5. Hsiao CC, Tsai ML, Chen CC, Lin HC (2014) Early optimal nutrition improves neurodevelopmental outcomes for very preterm infants. Nutr Rev 72:532-540. https://doi.org/10.1111/nure.12110

6. de Halleux V, Pieltain C, Senterre T, Studzinski F, Kessen C, Rigo V, Rigo J (2019) Growth benefits of own mother's milk in preterm infants fed daily individualized fortified human milk. Nutrients 11: 772. https://doi.org/10.3390/nu11040772

7. Underwood MA (2013) Human milk for the premature infant. Pediatr Clin N Am 60:189-207. https://doi.org/10.1016/j.pcl. 2012.09.008

8. Miller J, Tonkin E, Damarell RA, McPhee AJ, Suganuma M, Suganuma H, Middleton PF, Makrides M, Collins CT (2018) A systematic review and meta-analysis of human milk feeding and morbidity in very low birth weight infants. Nutrients 10:707. https://doi.org/10.3390/nu10060707 
9. Schanler RJ, Oh W (1980) Composition of breast milk obtained from mothers of premature infants as compared to breast milk obtained from donors. J Pediatr 96:679-681. https://doi.org/10.1016/ s0022-3476(80)80738-4

10. Bauer J, Gerss J (2011) Longitudinal analysis of macronutrients and minerals in human milk produced by mothers of preterm infants. Clin Nutr 30:215-220. https://doi.org/10.1016/j.clnu.2010.08.003

11. Gidrewicz DA, Fenton TR (2014) A systematic review and metaanalysis of the nutrient content of preterm and term breast milk. BMC Pediatr 14:216. https://doi.org/10.1186/1471-2431-14-216

12. Carratù B, Boniglia C, Scalise F, Ambruzzi A, Sanzini E (2003) Nitrogenous components of human milk: non-protein nitrogen, true protein and free amino acids. Food Chem 81:357-362. https://doi. org/10.1016/S0308-8146(02)00430-2

13. Pamblanco M, Portolés M, Paredes C, Ten A, Comín J (1989) Free amino acids in preterm and term milk from mothers delivering appropriate- or small-for-gestational-age infants. Am J Clin Nutr 50:778-781. https://doi.org/10.1093/ajcn/50.4.778

14. Zhang Z, Adelman AS, Rai D, Boettcher J, Lönnerdal B (2013) Amino acid profiles in term and preterm human milk through lactation: a systematic review. Nutrients 5:4800-4821. https://doi.org/ 10.3390/nu5124800

15. Pérez-Gálvez A, Calvo MV, Megino-Tello J, Aguayo-Maldonado J, Jiménez-Flores R, Fontecha J (2020) Effect of gestational age (preterm or full term) on lipid composition of the milk fat globule and its membrane in human colostrum. J Dairy Sci 103:7742-7751. https://doi.org/10.3168/jds.2020-18428

16. Akkerman R, Faas MM, de Vos P (2019) Non-digestible carbohydrates in infant formula as substitution for human milk oligosaccharide functions: effects on microbiota and gut maturation. Crit Rev Food Sci Nutr 59:1486-1497. https://doi.org/10.1080/10408398. 2017

17. Vandenplas Y, Berger B, Carnielli VP, Ksiazyk J, Lagström H, Sanchez Luna M, Migacheva N, Mosselmans JM, Picaud JC, Possner M, Singhal A, Wabitsch M (2018) Human milk oligosaccharides: 2'-fucosyllactose (2'-FL) and lacto-n-neotetraose (LNnT) in infant formula. Nutrients 10:1161. https://doi.org/10.3390/ nu10091161

18. Elwakiel M, Hageman JA, Wang W, Szeto IM, van Goudoever JB, Hettinga KA, Schols HA (2018) Human milk oligosaccharides in colostrum and mature milk of chinese mothers: Lewis positive secretor subgroups. J Agric Food Chem 66:7036-7043. https://doi. org/10.1021/acs.jafc.8b02021

19. Ferrer-Admetlla A, Sikora M, Laayouni H, Esteve A, Roubinet F, Blancher A, Calafell F, Bertranpetit J, Casals F (2009) A natural history of FUT2 polymorphism in humans. Mol Biol Evol 26: 1993-2003. https://doi.org/10.1093/molbev/msp108

20. Morrow AL, Meinzen-Derr J, Huang P, Schibler KR, Cahill T, Keddache M, Kallapur SG, Newburg DS, Tabangin M, Warner BB, Jiang X (2011) Fucosyltransferase 2 non-secretor and low secretor status predicts severe outcomes in premature infants. $\mathrm{J}$ Pediatr 158:745-751. https://doi.org/10.1016/j.jpeds.2010.10.043

21. Moukarzel S, Bode L (2017) Human milk oligosaccharides and the preterm infant: a journey in sickness and in health. Clin Perinatol 44:193-207. https://doi.org/10.1016/j.clp.2016.11.014

22. Bertino E, Coppa GV, Giuliani F, Coscia A, Gabrielli O, Sabatino G, Sgarrella M, Testa T, Zampini L, Fabris C (2008) Effects of holder pasteurization on human milk oligosaccharides. Int $\mathrm{J}$ Immunopathol Pharmacol 21:381-385. https://doi.org/10.1177/ 039463200802100216

23. Rodriguez NA, Meier PP, Groer MW, Zeller JM (2009) Oropharyngeal administration of colostrum to extremely low birth weight infants: theoretical perspectives. J Perinatol 29:1-7. https:// doi.org/10.1038/jp.2008.130

24. Dvorak B, Fituch CC, Williams CS, Hurst NM, Schanler RJ (2003) Increased epidermal growth factor levels in human milk of mothers with extremely premature infants. Pediatr Res 54:15-19. https://doi. org/10.1203/01.PDR.0000065729.74325.71

25. Cristofalo EA, Schanler RJ, Blanco CL, Sullivan S, Trawoeger R, Kiechl-Kohlendorfer U, Dudell G, Rechtman DJ, Lee ML, Lucas A, Abrams S (2013) Randomized trial of exclusive human milk versus preterm formula diets in extremely premature infants. $\mathrm{J}$ Pediatr 163:1592-1595.e1. https://doi.org/10.1016/j.jpeds.2013. 07.011

26. Schanler RJ, Lau C, Hurst NM, Smith EO (2005) Randomized trial of donor human milk versus preterm formula as substitutes for mothers' own milk in the feeding of extremely premature infants. Pediatrics 116:400-406. https://doi.org/10.1542/peds.2004-1974

27. Miller J, Tonkin E, Damarell RA, McPhee AJ, Suganuma M, Suganuma H, Middleton PF, Makrides M, Collins CT (2018) A systematic review and meta-analysis of human milk feeding and morbidity in very low birth weight infants. Nutrients 10:707. https://doi.org/10.3390/nu10060707

28. Villamor-Martínez E, Pierro M, Cavallaro G, Mosca F, Kramer BW, Villamor E (2018) Donor human milk protects against bronchopulmonary dysplasia: a systematic review and meta-analysis. Nutrients 10:238. https://doi.org/10.3390/nu10020238

29. Cañizo Vázquez D, Salas García S, Izquierdo Renau M, IglesiasPlatas I (2019) Availability of donor milk for very preterm infants decreased the risk of necrotizing enterocolitis without adversely impacting growth or rates of breastfeeding. Nutrients 11:1895. https://doi.org/10.3390/nu11081895

30. Giorgi MV, Codipilly CN, Potak D, Heiman HS, Schanler RJ (2018) Pasteurization preserves IL-8 in human milk. Front Pediatr 6:281. https://doi.org/10.3389/fped.2018.00281

31. Gila-Diaz A, Arribas SM, Algara A, Martín-Cabrejas MA, López de Pablo ÁL, Sáenz de Pipaón M, Ramiro-Cortijo D (2019) A review of bioactive factors in human breastmilk: a focus on prematurity. Nutrients 11:1307. https://doi.org/10.3390/nu11061307

32. Asbury MR, Butcher J, Copeland JK, Unger S, Bando N, Comelli EM, Forte V, Kiss A, LeMay-Nedjelski L, Sherman PM, Stintzi A, Tomlinson C, Wang PW, O'Connor DL (2020) Mothers of preterm infants have individualized breast milk microbiota that changes temporally based on maternal characteristics. Cell Host Microbe S1931-3128(20):30424-30428. https://doi.org/10.1016/j.chom. 2020.08.001

33. Valentine CJ, Morrow G, Reisinger A, Dingess KA, Morrow AL, Rogers LK (2017) Lactational stage of pasteurized human donor milk contributes to nutrient limitations for infants. Nutrients 9:302. https://doi.org/10.3390/nu9030302

34. Bulut Ö, Çoban A, İnce Z (2019) Macronutrient analysis of preterm human milk using mid-infrared spectrophotometry. J Perinat Med 47:785-791. https://doi.org/10.1515/jpm-2019-0105

35. Corvaglia L, Aceti A, Paoletti V, Mariani E, Patrono D, Ancora G, Capretti MG, Faldella G (2010) Standard fortification of preterm human milk fails to meet recommended protein intake: bedside evaluation by near-infrared-reflectance-analysis. Early Hum Dev 86:237-240. https://doi.org/10.1016/j.earlhumdev.2010.04.001

36. Henriksen C, Westerberg AC, Rønnestad A, Nakstad B, Veierød MB, Drevon CA, Iversen PO (2009) Growth and nutrient intake among very-low-birth-weight infants fed fortified human milk during hospitalisation. Br J Nutr 102:1179-1186. https://doi.org/10. 1017/S0007114509371755

37. Morlacchi L, Mallardi D, Giannì ML, Roggero $\mathrm{P}$, Amato O, Piemontese P, Consonni D, Mosca F (2016) Is targeted fortification of human breast milk an optimal nutrition strategy for preterm infants? An interventional study. J Transl Med 14:195. https://doi. org/10.1186/s12967-016-0957-y

38. Weber A, Loui A, Jochum F, Bührer C, Obladen M (2001) Breast milk from mothers of very low birthweight infants: variability in fat and protein content. Acta Paediatr 90:772-775. https://doi.org/10. 1111/j.1651-2227.2001.tb02803.x 
39. Rochow N, Fusch G, Zapanta B, Ali A, Barui S, Fusch C (2015) Target fortification of breast milk: how often should milk analysis be done? Nutrients 7:2297-2310. https://doi.org/10.3390/ nu7042297

40. Quigley M, Embleton ND, McGuire W (2019) Formula versus donor breast milk for feeding preterm or low birth weight infants. Cochrane Database Syst Rev 7(7):CD002971. https://doi.org/10. 1002/14651858.CD002971.pub5

41. Silano M, Milani GP, Fattore G, Agostoni C (2019) Donor human milk and risk of surgical necrotizing enterocolitis: a meta-analysis. Clin Nutr 38(3):1061-1066. https://doi.org/10.1016/j.clnu.2018. 03.004

42. Corpeleijn WE, de Waard M, Christmann V, van Goudoever JB, Jansen-van der Weide MC, Kooi EM, Koper JF, Kouwenhoven SM, Lafeber HN, Mank E, van Toledo L, Vermeulen MJ, van Vliet I, van Zoeren-Grobben D (2016) Effect of donor milk on severe infections and mortality in very low-birth-weight infants: The Early Nutrition Study Randomized Clinical Trial. JAMA Pediatr 170(7):654-661. https://doi.org/10.1001/jamapediatrics. 2016.0183

43. Patil S, Ananthan A, Nanavati RN, Nataraj G, Prasad P (2019) Effect of different methods of pasteurization on bactericidal action of human milk: a prospective observational study. Indian J Med Res 150(5):504-507. https://doi.org/10.4103/ijmr.IJMR 60018

44. Guerra AF, Mellinger-Silva C, Rosenthal A, Luchese RH (2028) Hot topic: holder pasteurization of human milk affects some bioactive proteins. J Dairy Sci 101(4):2814-2818. https://doi.org/10. 3168/jds.2017-13789
45. Baro C, Giribaldi M, Arslanoglu S, Giuffrida MG, Dellavalle G, Conti A, Tonetto P, Biasini A, Coscia A, Fabris C, Moro GE, Cavallarin L, Bertino E (2011) Effect of two pasteurization methods on the protein content of human milk. Front Biosci (Elite Ed) 3: 818-829. https://doi.org/10.2741/e289

46. Aceti A, Cavallarin L, Martini S, Giribaldi M, Vitali F, Ambretti S, Zambrini V, Corvaglia L (2020) Effect of alternative pasteurization techniques on human milk's bioactive proteins. J Pediatr Gastroenterol Nutr 70(4):508-512. https://doi.org/10.1097/MPG. 0000000000002598

47. Quitadamo PA, Palumbo G, Cianti L, Napolitano ML, Coviello C, Lurdo P, Copetti M, Gentile MA, Cristalli P (2018) Might the mothers of premature babies feed them and devote some milk to the milk bank? Int J Pediatr 2018:3628952. https://doi.org/10.1155/ 2018/3628952

48. Nangia S, Ramaswamy VV, Bhasin M (2020) The profile of donors to a human milk bank in a developing nation. Breastfeed Med 15: 135-139. https://doi.org/10.1089/bfm.2019.0212

49. Pimenteira Thomaz AC, Maia Loureiro LV, da Silva Oliveira T, Furtado Montenegro NC, Dantas Almeida Júnior E, Fernando Rodrigues Soriano C, Calado Cavalcante J (2008) The human milk donation experience: motives, influencing factors, and regular donation. J Hum Lact 24:69-76. https://doi.org/10.1177/ 0890334407310580

Publisher's note Springer Nature remains neutral with regard to jurisdictional claims in published maps and institutional affiliations. 